\title{
Penetrating Keratoplasty after Radial Keratotomy and Recurrent Immune Overreaction
}

\author{
Raffaele Nuzzi Elisa Buschini \\ Section of Ophthalmology, Department of Clinical Pathophysiology, University of Turin, \\ Turin, Italy
}

\section{Key Words}

Penetrating keratoplasty - Radial keratotomy - Keratoconus - Traumatic memory . Recurrent immune overreaction · Kerato-uveitis

\begin{abstract}
A 32-year-old man suffering from keratoconus was treated with radial keratotomy. Twenty weeks later, he presented visual deterioration, edema and corneal perforation. A penetrating keratoplasty was required. The postoperative course was regular, but after 9 months, the patient presented kerato-uveitis. Subsequent phlogistic relapses occurred approximately every 6 months during the following 5 years. The performed cultures were positive only during the first episode. Radial keratotomy is not indicated in keratoconus. The multiple relapses of kerato-uveitis could not be explained by infection, and we hypothesized that they may be due to a 'traumatic memory' of the cornea caused by the several suffered traumatisms, without clinical features of corneal graft rejection. The risks of new penetrating keratoplasty and cataract surgery are high. As the cornea is the tissue with the highest sensitivity in the body, we tried to explain the relapsing kerato-uveitis as a consequence of the disruption of the nervous corneal network.
\end{abstract}

\section{Introduction}

Keratoconus $(\mathrm{KCN})$ is a progressive, noninflammatory, multifactorial ectatic condition of the cornea [1]. Treatment options for initial or mild disease include contact lenses or, if these are not tolerated, the insertion of implants in the corneal periphery to change the curvature. Advanced disease is nowadays treated with different techniques, depending on the specific condition of the cornea. Finally, corneal transplants (penetrating keratoplasty or lamellar keratoplasty) are the only option when other treatments have failed [2]. The cornea is densely innervated with sensory nerve fibers, which probably have more than a purely sensory role. Dynamic processes operate at various levels: the resident cells and the regulation by nerves create a network that contributes to the maintenance of the normal structure and functions as well as to the repair of injuries [3]. The disruption of these 
mutual interactions due to $\mathrm{KCN}$ and to surgical treatment could alter the corneal immune response.

\section{Case Report}

A 32-year-old man was referred to the Turin Eye Clinic for decreased vision. His ocular history was positive for bilateral KCN since 6 years. At diagnosis, the right corneal central thickness was $480 \mu \mathrm{m}$ and the left one was $415 \mu \mathrm{m}$. As KCN progressed, contact lenses became uncomfortable, especially in the left eye. The patient refused the main therapeutic options and together with his referring ophthalmologist, he decided to have a left radial keratotomy (contrary to the actual guidelines). At presentation, 20 weeks later, the left best corrected visual acuity (BCVA) was finger counting. The cornea presented 16 paracentral scars, radial from 2 to 10 o'clock ( $\underline{\text { fig. }} \mathbf{1 a}$, b), white opacity in the stroma, and edema with folds of the Descemet membrane. The depth of incision was $90 \%$ of corneal thickness, and the Seidel test was positive. A penetrating keratoplasty was required. After 7 months, the patient complained of red eye and decreased vision in the left eye. His BCVA was 1/50. Conjunctival hyperemia, hordeolum on the inferior lid, edema and increased thickness of the corneal graft and of the folds of the Descemet membrane were observed. Flare and anterior chamber reaction was $2+$, and keratic precipitates were present in the endothelium. Cultures identified colonies of coagulase-negative Staphylococcus. Therapy consisted of oral prednisone and cyclosporine A, topical drops of cyclosporine A, netilmicin, corticosteroid, $1 \%$ atropine and subconjunctival injections of dexamethasone. After 15 days, the corneal edema decreased and the drugs were progressively reduced. His BCVA was 8/10.

During the following 5 years, the patient reported recurrent anterior kerato-uveitis in the left eye (approximately one every 6 months). All these relapses were characterized by intense phlogistic reactions, loss of clarity of the corneal graft and corneal decompensation, with a high risk of corneal graft rejection which may have necessitated a second penetrating keratoplasty. All the cultures taken during the relapses were negative, and a concurrent presence of hordeolum was not found. Thereafter, all these events were treated with the same medical therapy used for the first one. Recovery with corneal transparency and regain of the same visual acuity, which the patient had achieved after the penetrating keratoplasty, were obtained. Furthermore, no clinical features of corneal graft rejection were observed.

\section{Discussion}

Radial keratotomy is a refractive corneal surgical procedure used to treat different degrees of myopia. Radial keratotomy for KCN has not been attempted because of its poor record and results. However, penetrating keratoplasty has been highly successful in most case series $[4,5]$. Corneal transplantation is considered the standard treatment when nonsurgical modalities, such as glasses and contact lenses, have failed; surgical intervention in $\mathrm{KCN}$ is indicated when the patient can no longer achieve good visual acuity through these means. Over $80 \%$ of patients undergoing penetrating keratoplasty for KCN obtain a visual acuity of 20/40 or better. On the contrary, radial keratotomy structurally compromises the eye. Since it appears that pathologic alterations in corneas with $\mathrm{KCN}$ encourage scar formation in the area of incision, using radial keratotomy to delay penetrating keratoplasty in $\mathrm{KCN}$ cases does not appear to be an effective treatment strategy. It should also be emphasized that performing radial keratotomy in an eye with KCN may cause difficulty in performing a subsequent corneal transplant into an unstable, irregular recipient bed. It may result in increased astigmatism and potential problems with wound healing [6]. The medical literature points to known KCN and similar corneal degenerative diseases as contraindications to LASIK. Shaikh et al. [7] are of the opinion that keratotomy should also be approached with caution in suspected KCN. Cases have been reported documenting the development of iatrogenic KCN after uneventful radial keratotomy, possibly requiring subsequent penetrating keratoplasty [7-9]. Radial 
keratotomy should also be denied to patients with other underlying ocular diseases, because subsequent surgery may be rendered more difficult by the presence of corneal incisions. Experimental studies and case reports suggest that corneas may be more susceptible to traumatic rupture even many years following radial keratotomy, particularly if a microperforation occurred [10,11]. Shivitz and Arrowsmith [12] suggest that incisional refractive surgery results in a loss of corneal sensation leading to decreased tear secretion and increased stress in the ocular surface epithelium. They found that radial keratotomy reduces corneal sensitivity, and that astigmatic keratotomy causes a greater decrease in corneal sensitivity since more corneal nerves are transected. Moreover, decreased corneal sensation after keratotomy may reduce corneal epithelial mitosis and wound healing. All of these changes to the cornea might increase the risk of infection and of graft failure.

Furthermore, another factor that could be involved is eye rubbing. Eye rubbing has been recognized as a factor causing repeated corneal trauma, which involves an inflammatory response with local increase of immune system mediators and abnormalities in keratocytes. Recurrent and intense episodes of eye rubbing could cause relapsing KCN or development of postoperative complications [13].

In our patient, we initially hypothesized that the first episode of anterior kerato-uveitis was caused by the invasion of Staphylococcus from the conjunctival flora: he had recently been affected by a hordeolum on the inferior lid that subsequently could have evolved into a kerato-uveitis. However, because of the subsequent relapses (approximately one every 6 months), we always found negative cultures, so we did not identify any infective causes that could explain the etiology of the kerato-uveitis. The cornea is the tissue with the highest sensitivity in the entire body, as it is densely innervated with sensory nerve fibers. A number of clinical observations have been recorded which suggest that corneal nerves may have more than a purely sensory role. Although the cornea appears to be a relatively static structure, dynamic processes operate at various levels. The resident cells of the cornea (epithelial cells, keratocytes and endothelial cells) also engage in mutual interactions through network systems. These interactions as well as those with infiltrated cells and regulation by nerves contribute to the maintenance of the normal structure and functions of the cornea as well as to the repair of corneal injuries. Progress in cell and molecular biology has allowed the characterization of the dynamic network systems including cell-cell and cell-extracellular matrix interactions as well as cytokines and neural factors which contribute to the maintenance of the corneal transparency and shape [3].

Soluble cytokines and growth factors are produced by endothelial cells and keratocytes and are involved in stroma-epithelium interactions, differentiation, proliferation and cell motility. The corneal sensory innervation probably acts through soluble mediators released from axon terminals, such as substance $P$ that binds receptors on epithelial cells [14]. In the normal cornea, a low number of inflammatory cells is usually found. As corneal damage occurs, the expression of these factors increases and causes the recruitment of immune cells. Furthermore, $\mathrm{KCN}$ and eye rubbing cause chronic release of cytokines by the epithelium. Corneal trauma associated with corneal refractive surgery is linked to accumulation of inflammatory cells and distortion of neural circuits with reduced production of neurotrophic factors. Corneal denervation has been shown to induce keratitis in monkeys [15]. 
With hindsight, concerning our patient, we may discard the infective etiology and hypothesize that the radial incisions of the radial keratotomy had disrupted the nervous corneal network because many corneal nerves were transected. The subsequent perforation followed by penetrating keratoplasty has finally distorted the organized structure of the corneal components, the dynamic processes of neural regulation and cytokines interactions.

Our patient did not report episodes of intense eye rubbing, but probably the continuous trauma due to normal eyelid movement, acting on a frail and impaired cornea, was a factor of primary and secondary damage, facilitating progression and recurrence of the disease and the subsequent inflammatory events.

All these conditions may have created a sort of 'memory' of the suffered traumatisms leading to the development of the first episode of anterior kerato-uveitis and the subsequent relapses of phlogistic reactions with an immune etiology, without clinical features of corneal graft rejection. The risks of new penetrating keratoplasty and cataract surgery are high.

\section{Disclosure Statement}

The authors have no conflicts of interest to declare. 


\begin{tabular}{c|l|l|l}
$\begin{array}{c}\text { Case Reports in } \\
\text { Ophthalmology }\end{array}$ & $\begin{array}{l}\text { Case Rep Ophthalmol 2011;2:123-128 } \\
\text { DOI: 10.1159/000324750 }\end{array}$ & $\begin{array}{l}\text { Published online: } \\
\text { April 11, 2011 }\end{array}$ & $\begin{array}{l}\text { O 2011 S. Karger AG, Basel } \\
\text { ISSN 1663-2699 } \\
\text { www.karger.com/cop }\end{array}$ \\
\hline
\end{tabular}
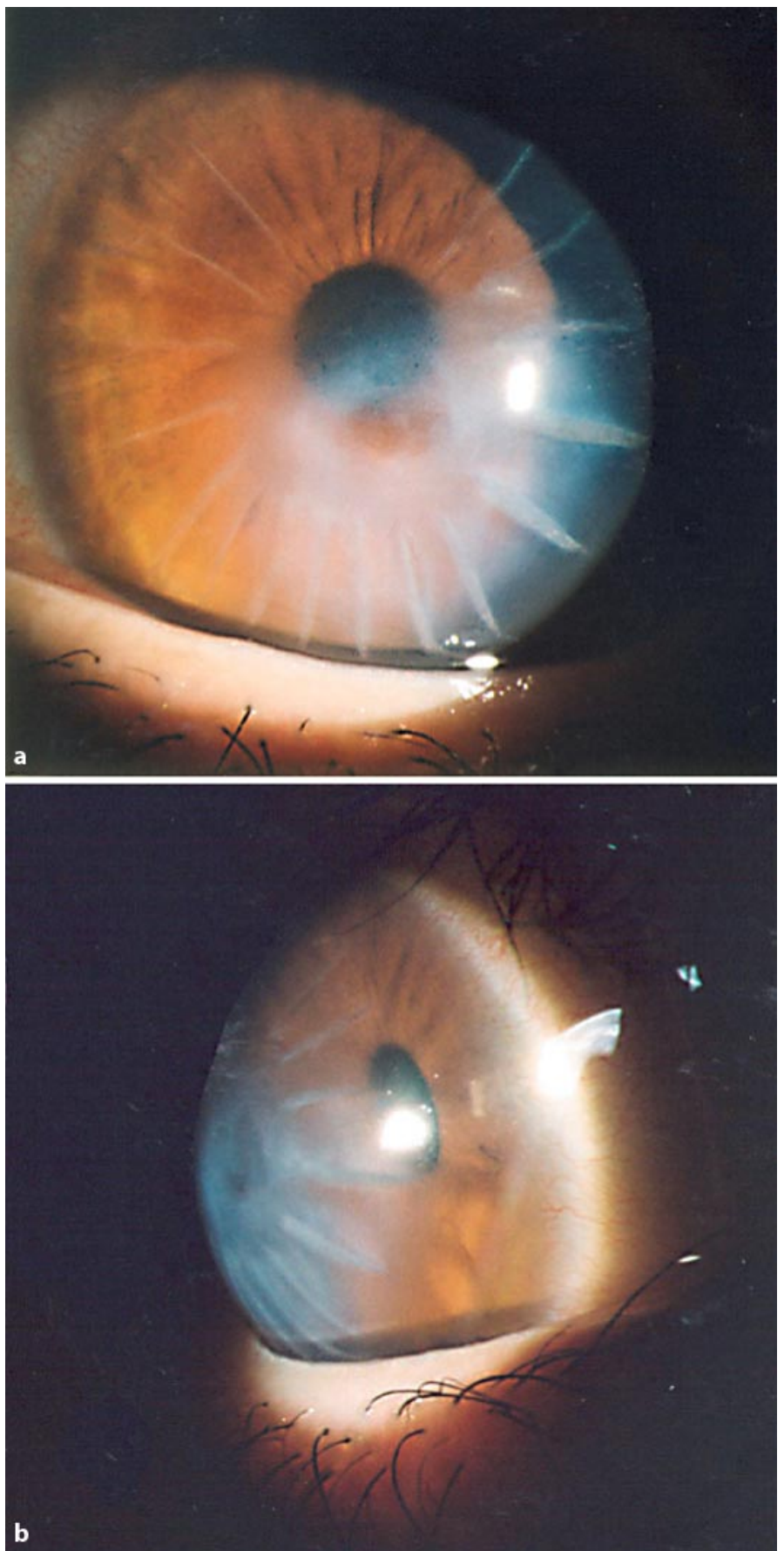

Fig. 1. Corneal findings of 16 radial paracentral scars, white opacity at the superficial and deep corneal stroma, corneal edema and folds of the Descemet membrane. Frontal (a) and lateral (b) view. 


\section{References}

1 Weed KH, McEwen CJ, Giles T, Low J, McGhee CN: The Dundee University Scottish Keratoconus study: demographics, corneal signs, associated diseases, and eye rubbing. Eye 2008;22:534-541.

-2 Lois N, Kowal VO, Cohen EJ, Rapuano CJ, Gault JA, Raber IM: Indications for penetrating keratoplasty and associated procedures, 1989-1995. Cornea 1997;16:623-629.

-3 Nishida T: The cornea: stasis and dynamics. Nippon Ganka Gakkai Zasshi 2008;112:179-212.

4 Durand L, Monnot JP, Burillon C, Assi A: Complications of radial keratotomy: eyes with keratoconus and late wounds dehiscence. Refract Corneal Surg 1992;8:311-314.

-5 Wagoner MD, Ba-Abbad R, Al-Mohaimeed M, Al-Swailem S, Zimmerman MB: King Khaled Eye Specialist Hospital Cornea Transplant Study Group. Postoperative complications after primary adult penetrating keratoplasty: prevalence and impact on graft survival. Cornea 2009;28:385-394.

-6 Kubaloglu A, Koytak A, Sogutlu E, Kurnaz E, Ozerturk Y: Penetrating keratoplasty in keratoconic eyes with prior radial keratotomy. Eur J Ophthalmol 2010;20:35-40.

7 Shaikh S, Shaikh NM, Manche E: Iatrogenic keratoconus as a complication of radial keratotomy. J Catarect Refract Surg 2002;28:553-555.

-8 Muñoz G, Montes-Mico R, Albarran-Diego C, Alió JL: Keratectasia after bilateral laser in situ keratomileusis in a patient with previous radial and astigmatic keratotomy. J Cataract Refract Surg 2005;31:441-445.

>9 Klein SR, Epstein RJ: Ectasia after photorefractive keratectomy. Ophthalmology 2007;114:395-396.

10 Panda A, Sharma N, Kumar A: Ruptured globe 10 years after radial keratotomy. J Refract Surg 1999;15:64-65.

11 Artola A, Ayala MJ, Ruiz-Moreno JM, De La Hoz F, Alió JL: Rupture of radial keratotomy incisions by blunt trauma 6 years after combined photorefractive keratectomy/radial keratotomy. J Refract Surg 2003;19:460-462.

12 Shivitz IA, Arrowsmith PN: Corneal sensitivity after radial keratotomy. Opthalmology 1988;95:827-832.

13 McMonnies CW: Mechanisms of rubbing-related corneal trauma in keratoconus. Cornea 2009;28:607-615.

14 Garcia-Hirschfeld J, Lopez-Briones LG, Belmonte C: Neurotrophic influences on corneal epithelial cells. Exp Eye Res 1994;59:597-605.

15 Lim CH: Innervation of the cornea of monkeys and the effects of denervation. Br J Physiol Opt 1976;31:38-42. 